\title{
Wind Farm Layout Optimization Using Sound Pressure Level Constraints
}

\author{
Eric Tingey \\ Brigham Young University, ebtingey@gmail.com \\ Jared Thomas \\ Brigham Young University, jaredthomas68@gmail.com \\ Andrew Ning \\ Brigham Young University, aning@byu.edu
}

Follow this and additional works at: https://scholarsarchive.byu.edu/facpub

Part of the Mechanical Engineering Commons

\section{Original Publication Citation}

Tingey, E., Thomas, J., and Ning, A., "Wind Farm Layout Optimization Using Sound Pressure Level Constraints," IEEE Conference on Technologies for Sustainability, Ogden, UT, Jul. 2015. doi:10.1109/SusTech.2015.7314339

\section{BYU ScholarsArchive Citation}

Tingey, Eric; Thomas, Jared; and Ning, Andrew, "Wind Farm Layout Optimization Using Sound Pressure Level Constraints" (2015). Faculty Publications. 1723.

https://scholarsarchive.byu.edu/facpub/1723

This Conference Paper is brought to you for free and open access by BYU ScholarsArchive. It has been accepted for inclusion in Faculty Publications by an authorized administrator of BYU ScholarsArchive. For more information, please contact ellen_amatangelo@byu.edu. 


\title{
Wind Farm Layout Optimization Using Sound Pressure Level Constraints
}

\author{
Eric B. Tingey, Jared J. Thomas and Andrew Ning \\ Department of Mechanical Engineering \\ Brigham Young Univeristy \\ Provo, Utah, USA \\ Email: ebtingey@byu.edu
}

\begin{abstract}
This project explored wind farm layout optimization using turbine acoustic and wake models. For two existing wind farms, the position of each wind turbine was optimized to maximize power output while constraining noise. Semi-empirical calculations were used for both the acoustic and wake models to predict how the turbine noise and wake disturbances propagated downstream. Turbine layout was optimized using a sequential quadratic programming optimizer called SNOPT. The optimization was able to constrain the noise level of the wind farms with a small impact on power output.
\end{abstract}

Keywords-wind turbine; acoustic modeling; wake propagation; wake modeling; turbine plant optimization

\section{INTRODUCTION}

Wind energy is a valuable source of power as it is renewable, available in many parts of the world, and has the ability to produce twenty times more power than the world currently consumes [1]. To harness large amounts of wind energy, wind turbines are grouped in wind farms. However, as each turbine extracts energy from the wind, it causes a reduction in wind speed and an increase in turbulence downstream. The air that is affected by the turbine is called the turbine wake. A turbine's wake causes a significant reduction in the power production of nearby and downwind turbines. Therefore, the turbines must be placed in such a way that the wake interference does not decrease the power production of other turbines [1]. Predicting how these wakes propagate, through wake modeling, becomes important to the overall efficiency of the wind farm.

Wind turbine noise generation is another important consideration. This noise can cause disturbances to residential areas located in the vicinity of wind farms. There are many contributors to the turbine noise, including mechanical noise from the generator and tower-wake interaction noise caused by the wake of the rotating blades, but the turbulent-induced noise from the wind flowing over the blades is the main contributor of the turbine noise [2]. While the sound coming from wind turbines poses little physical or psychological harm to humans, it can be an annoyance to individuals living nearby wind farms [3]. Ideally, a wind farm layout should constrain the level of turbine noise disturbance to nearby residential areas below a specific limit while maximizing power output.

Using wake and acoustic modeling, we explored the tradeoffs of reducing the noise level while maximizing power output through changing the positions of the turbines. We constrained the turbine noise to a specified level between 35 to $40 \mathrm{~dB}$, which was recommended by the European region of the World Health Organization [4]. Previous research has performed a simple analysis of turbine optimization with the Jensen wake model and the ISO-9613-2 standard for acoustic propagation [5]. Because the ISO-9613-2 standard only predicts how sound propagates and not how it is created, our research used an acoustic model based on the BPM equations [6] that described how sound was created and propagated for results based more on turbines in operation. This study also used a wake model that described the decay and movement of the wake downstream more accurately than the Jensen model. The optimization conducted in [5] uses a grid-based optimization which only allows turbines to be in discrete locations. Our optimization allowed the turbines to move freely within the bounds designated by the wind farm. With these types of models and optimization, we were able to more effectively study how to better position turbines in a wind farm to increase the plant efficiency while limiting the noise disturbance to nearby residential areas.

\section{METHODS}

\section{A. Locations}

In an effort to make the research applicable to a real-world situation, we used two actual wind farms as models for our optimization scheme. They were selected due to problems they have had with turbine noise annoyance as described in [7] and [8]. The first one was based on the Lissett Airfield Wind Farm in East Yorkshire, England which was constructed on a former Royal Air Force airfield and is now run by Infinis [9] (Fig. 1). It was found that high wind speeds in certain directions caused an increase in turbine noise, so efforts were made to reduce the noise by slowing the turbine rotation [7]. Slowing the turbines down decreases the turbine noise, but it also decreases power production. Instead, we explored the potential benefits of considering the acoustic impacts during the initial layout process rather than fixing the noise problem later on.

The specifications of this plant included twelve turbines with $90 \mathrm{~m}$ rotor diameters [10]. The actual wind farm boundary follows the curves of the property line of the former airfield, but we simplified the wind farm boundaries to a square area for our optimization. To act as points of sound measurements, 


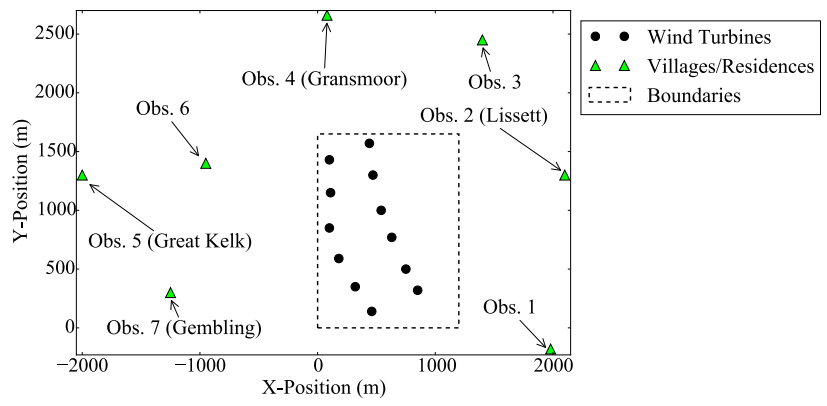

Fig. 1. An approximation of the layout of the Lissett Airfield Wind Farm used as a reference in our first study. Each of the seven observer locations used for the sound measurements are indicated.

we chose seven villages and residences located near the wind farm as seen in Fig. 1.

The second wind farm was based on the Rosiere Wind Farm run by Madison Gas and Electric in Kewaunee County, Wisconsin (Fig. 2). This location was interesting in that individuals who lease the land to the company still live within the bounds of the wind farm rather than living outside the bounds. They even plant crops right up to the base of the turbines [11]. Since noise control would be important for individuals living so close to the turbines, we looked for a way to position each turbine to reduce noise while keeping the turbines within the limits of their respective leased property.

The specifications of this plant include seventeen turbines with $46.9 \mathrm{~m}$ (154 ft) rotor diameters [11]. Simplifications were also made on this farm's boundaries to straighten the slightly curved property lines. Twelve residential locations were used as the sound measurement locations and can be seen in Fig. 2 to be located within the turbine boundaries in many cases.

Initial power and noise levels were calculated based on the original positions of each of the turbines and the observer locations, which can be seen in Table I. In an actual wind farm optimization, the need to account for all wind directions would be important as a slight change in wind direction may cause a notable difference in power output. However, for the scope of this initial research, we used only the predominant wind direction at both of the wind farms with the intention to later expand the research to account for all wind directions. The predominant wind of the Lissett Airfield Wind Farm was in the south-southwest direction at about $5 \mathrm{~m} / \mathrm{s}$ as reported by a nearby weather station [12] and the predominant wind of the Rosiere Wind Farm was in the west-southwest direction at about $6.5 \mathrm{~m} / \mathrm{s}$ [13].

\section{B. Wake and Acoustic Models}

For the wake modeling, we used the FLOw Redirection and Induction in Steady-state (FLORIS) model. This wake model works by splitting the wake into different zones called the near wake, the far wake, and the mixing zone. It also accounts for decay and offset of the wake propagation assuming constant properties in the cross-wind direction of each zone [14]. Due to the lack of information we had on the actual turbines at both wind farms, we used the parameters found in [14].

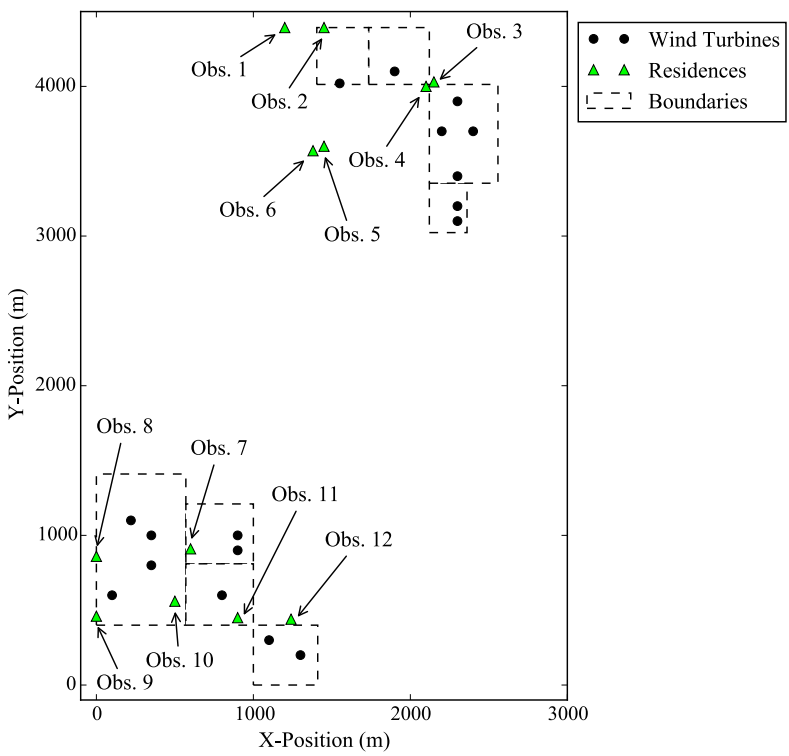

Fig. 2. An approximation of the layout of the Rosiere Wind Farm used as a reference in our second study. Each of the twelve observer locations used for the sound measurements are indicated.

One exception was the rotor diameter, which used the actual turbine rotor diameter. Because of the lack of data, our findings may not provide the exact power output that the wind farms produce, but the results give a meaningful comparison showing the impact of acoustic constraints.

The acoustic model used in this research was based on the BPM equations developed by Brooks, Pope, and Macolini [6]. These equations produce a semi-empirical acoustic model based on experimentation that was conducted using NACA 0012 airfoil data. This model was further studied by other researchers, such as Moriarty and Migliore with NREL who compared the NACA 0012 data to other blade cross-sections

TABLE I. Initial Layout MEasurements

\begin{tabular}{llll}
\hline \multicolumn{4}{c}{ Lissett Airfield Wind Farm } \\
\hline \hline \multicolumn{4}{c}{ Overall Power Output: 9.66 MW } \\
\hline Sound Pressure Levels \\
\hline Observer 1 & $32.4 \mathrm{~dB}$ & Observer 5 & $27.8 \mathrm{~dB}$ \\
Observer 2 & $34.6 \mathrm{~dB}$ & Observer 6 & $37.6 \mathrm{~dB}$ \\
Observer 3 & $36.1 \mathrm{~dB}$ & Observer 7 & $34.8 \mathrm{~dB}$ \\
Observer 4 & $37.0 \mathrm{~dB}$ & & \\
\hline
\end{tabular}

\begin{tabular}{llll}
\multicolumn{4}{c}{ Rosiere Wind Farm } \\
\hline \hline \multicolumn{4}{c}{ Overall Power Output: 3.97 MW } \\
\hline Sound Pressure Levels \\
\hline Observer 1 & $28.0 \mathrm{~dB}$ & Observer 7 & $47.6 \mathrm{~dB}$ \\
Observer 2 & $36.1 \mathrm{~dB}$ & Observer 8 & $45.2 \mathrm{~dB}$ \\
Observer 4 & $45.5 \mathrm{~dB}$ & Observer 9 & $51.5 \mathrm{~dB}$ \\
Observer 5 & $47.5 \mathrm{~dB}$ & Observer 10 & $44.4 \mathrm{~dB}$ \\
Observer 6 & $34.1 \mathrm{~dB}$ & Observer 11 & $47.7 \mathrm{~dB}$ \\
\hline
\end{tabular}




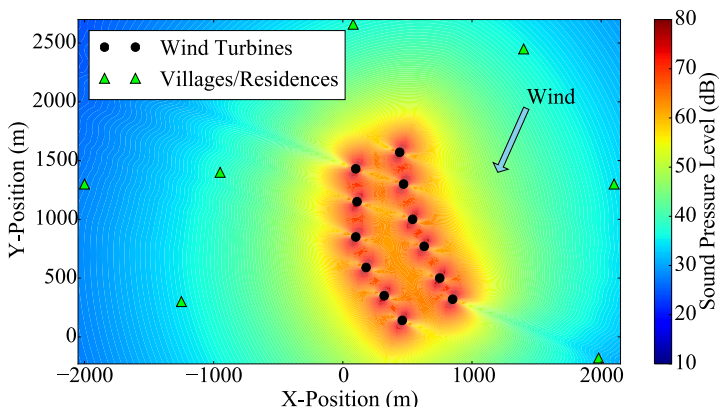

Fig. 3. The sound pressure level (SPL) distribution of the Lissett Airfield Wind Farm with the turbines at their original locations.

[15]. They found that the most accurate results from the BPM equations were obtained when using a NACA 0012 blade cross-section. Because the original BPM equations were developed using the NACA 0012 blade data, any changes to the blade cross-section resulted in less accurate acoustic results [15]. Since the turbines used at the two wind farms do not use NACA 0012 blades, as described in [10], [11], efforts were made to validate the acoustic model against other known values, such as results published by the Rosiere Wind Farm that $47 \mathrm{~dB}$ could be heard 243.8 meters ( 800 feet) downwind of a turbine [11]. As with the wake modeling, the acoustic model may not account for the wind farm's complete noise distribution, but it does provide sufficient acoustic measurements for use in optimization comparison.

The BPM equations produce a sound pressure level (SPL) in decibels based on different aspects of a wind turbine, such as rotation rate and blade shape, and the orientation and distance an observer is from the noise created [6]. The sources of sound in this study included turbulence from blade along the trailing edges and at the tips as well as the vortex shedding of the boundary layer and trailing edge bluntness. Figs. 3 and 4 show the SPL distribution in the two wind farms using this acoustic model.

\section{Optimization}

Using the FLORIS and BPM models, the optimization was performed using SNOPT, a sequential quadratic programming optimizer used for solving large, nonlinear problems [11]. The optimization was defined by:

$$
\begin{aligned}
\text { maximize } & P(x, y) \\
\text { with respect to } & x_{i}, y_{i}, \quad i=0,1, \ldots, m \\
\text { subject to } & d_{i, j} \geq 2 D_{\text {turbine }}, \quad i, j=0,1, \ldots, m \\
& B_{x, \text { low }} \leq x_{i} \leq B_{x, \text { high }} \quad i=0,1, \ldots, m \\
& B_{y, \text { low }} \leq y_{i} \leq B_{y, \text { high }}, \quad i=0,1, \ldots, m \\
& S P L_{k} \leq S P L_{\text {limit }}, \quad k=0,1, \ldots, n
\end{aligned}
$$

where $P(x, y)$ is the overall turbine power output, using the FLORIS wake model, based on the $x$ and $y$ locations of each of the $m$ turbines in the wind farm. The distance between turbines $i$ and $j\left(d_{i, j}\right)$ was set to be two times the turbine

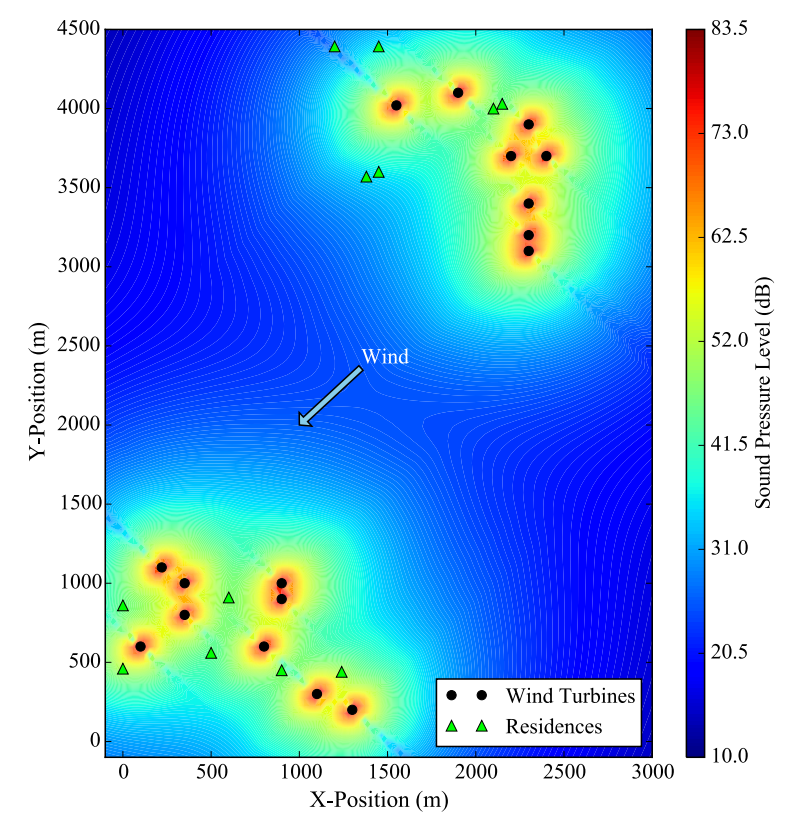

Fig. 4. The sound pressure level (SPL) distribution of the Rosiere Wind Farm with the turbines at their original locations.

diameter $\left(D_{\text {turbine }}\right)$. The turbines were constrained between the lower and upper $x$ and $y$ boundaries of the wind farm limits $\left(B_{x, \text { low }}, B_{x, \text { high }}, B_{y, \text { low }}\right.$, and $\left.B_{y, \text { high }}\right)$. The SPL at each of the $n$ observers was constrained to be less than $40 \mathrm{~dB}$ in the Rosiere Wind Farm. In the Lissett Airfield Wind Farm, since the observers are all below $40 \mathrm{~dB}$ to begin with (see Table I), the lower level of $35 \mathrm{~dB}$ was used as the SPL constraint.

\section{RESULTS}

The optimization was run twice based on (1), with and without the SPL constraint. This was done to compare the power production with no noise limit enforced to the power production using the noise constraint. Doing this gave us a better idea of how the acoustics impacted the optimal layout and how close the power output was to the unconstrained maximum value.

\section{A. Optimization of the Lissett Airfiled Wind Farm}

For the Lissett Airfiled Wind Farm, the optimal positions of the turbines can be seen in Fig. 5 for the SPL-constrained and unconstrained cases. Using the original turbine locations as the starting points for optimization, the turbines did not move significantly in the unconstrained case. This indicated that the turbines were already fairly optimized for power output with the single wind direction. By moving the turbines slightly, the optimizer was able to increase the power output by $8.72 \%$ (see Table II). In the constrained case, the SPLs were all brought within the limit of $35 \mathrm{~dB}$, as shown in Fig. 6, by moving the turbines towards the southern end of the wind farm (see Fig. 5). Lowering the sound levels by adding the SPL constraint did not have a detrimental effect on power production as it 

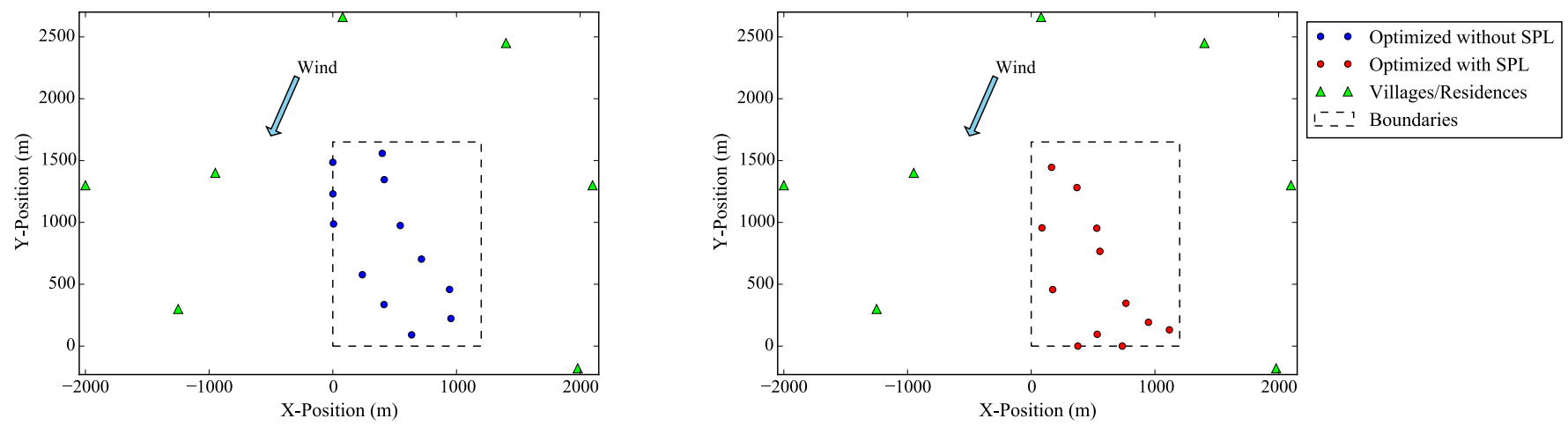

Fig. 5. The optimized layout of the Lissett Airfield Wind Farm showing the optimized locations of the turbines without the SPL constraint in blue and with the SPL constraint in red.
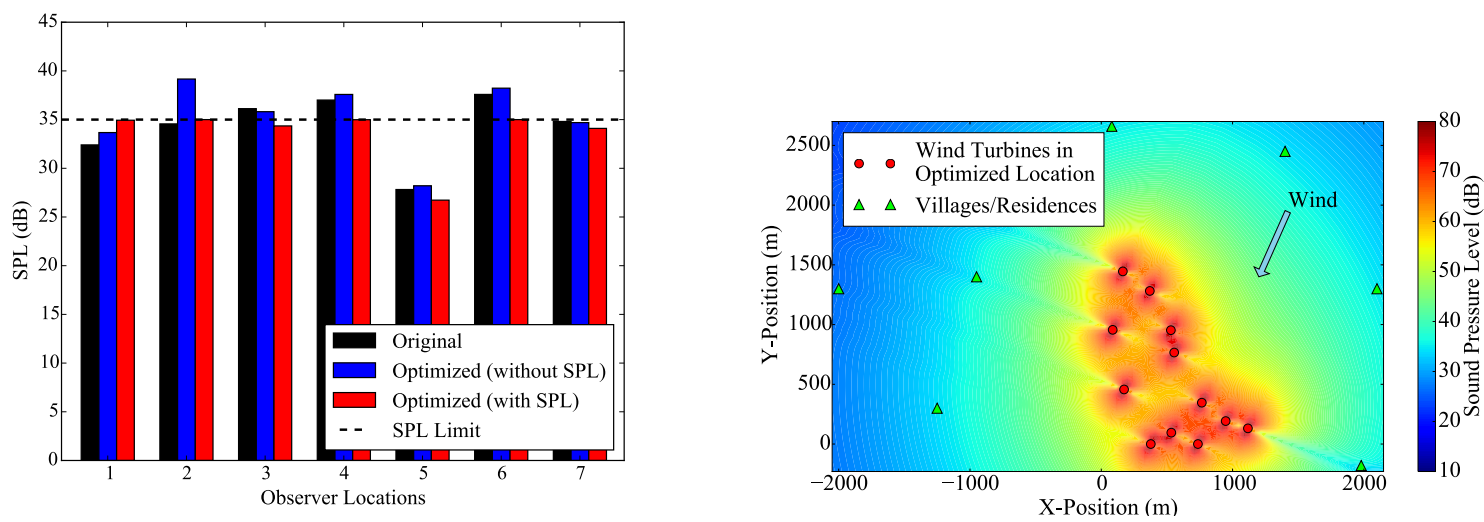

Fig. 6. Results from SPL optimization of the Lissett Airfield Wind Farm. The figure on the left shows a comparison of SPL between the original layout, the optimized layout without SPL constraints, and the optimized layout with SPL constraints. The figure on the right shows the SPL distribution of the Lissett Airfield Wind Farm with the turbines at their optimal locations when the SPL constraint was enforced.

TABLE II. OVERALl POWER AND AVERAGE SPL COMPARISON OF THE LISSETT AIRFIELD WIND FARM

\begin{tabular}{lccc}
\hline Optimization Scheme & Power Output & Percent Increase & Average SPL \\
\hline Original & $9.656 \mathrm{MW}$ & - & $34.3 \mathrm{~dB}$ \\
Without SPL Constraint & $10.498 \mathrm{MW}$ & $8.72 \%$ & $35.3 \mathrm{~dB}$ \\
With SPL Constraint & $10.498 \mathrm{MW}$ & $8.72 \%$ & $33.6 \mathrm{~dB}$ \\
\hline
\end{tabular}

remained the same (see Table II). The new SPL distribution is shown in Fig. 6.

\section{B. Optimization of the Rosiere Wind Farm}

We found the same type of results for the Rosiere Wind Farm with some differences. Without the SPL constraint, the turbines all stayed in about the same place with slight variations (see Fig. 7). This was similar to the results seen in the optimization of the Lissett Airfield Wind Farm. The power production in this layout increased by $1.79 \%$, as seen in Table III.

Including the SPL constraint in the optimization moved the turbines to the edges of the property limits, as seen in Fig. 7. The locations near the boundaries of the wind farm were the best places for the turbines where fewer observers were situated. The SPL limits were all satisfied after the optimization with significant SPL reductions, and the new SPL distribution can be seen in Fig. 8. However, the power output decreased slightly by $0.4 \%$ compared to the unconstrained case.

Looking at this wind farm with a single wind direction, we concluded that while constraining the noise to $40 \mathrm{~dB}$ does have a slight decrease in power output, the tradeoff with the decrease in power brings significant SPL reductions. There was an average decrease of $9.1 \mathrm{~dB}$ overall (see Table III) and large SPL reductions at several observers as seen in Fig. 8. This type of situation would need to be considered by a wind farm in designing their turbine layout. They would have to decide if the impact in power output would be worth the noise reduction. An alternative would be enforcing a higher SPL limit, if it were acceptable by residents nearby, allowing the turbines to produce more power.

TABLE III. OVERALl POWER AND AVERAGE SPL COMPARISON OF THE ROSIERE WIND FARM

\begin{tabular}{lccc}
\hline Optimization Scheme & Power Output & Percent Increase & Average SPL \\
\hline Original & $3.974 \mathrm{MW}$ & - & $42.9 \mathrm{~dB}$ \\
Without SPL Constraint & $4.045 \mathrm{MW}$ & $1.79 \%$ & $44.9 \mathrm{~dB}$ \\
With SPL Constraint & $4.029 \mathrm{MW}$ & $1.39 \%$ & $35.8 \mathrm{~dB}$ \\
\hline
\end{tabular}



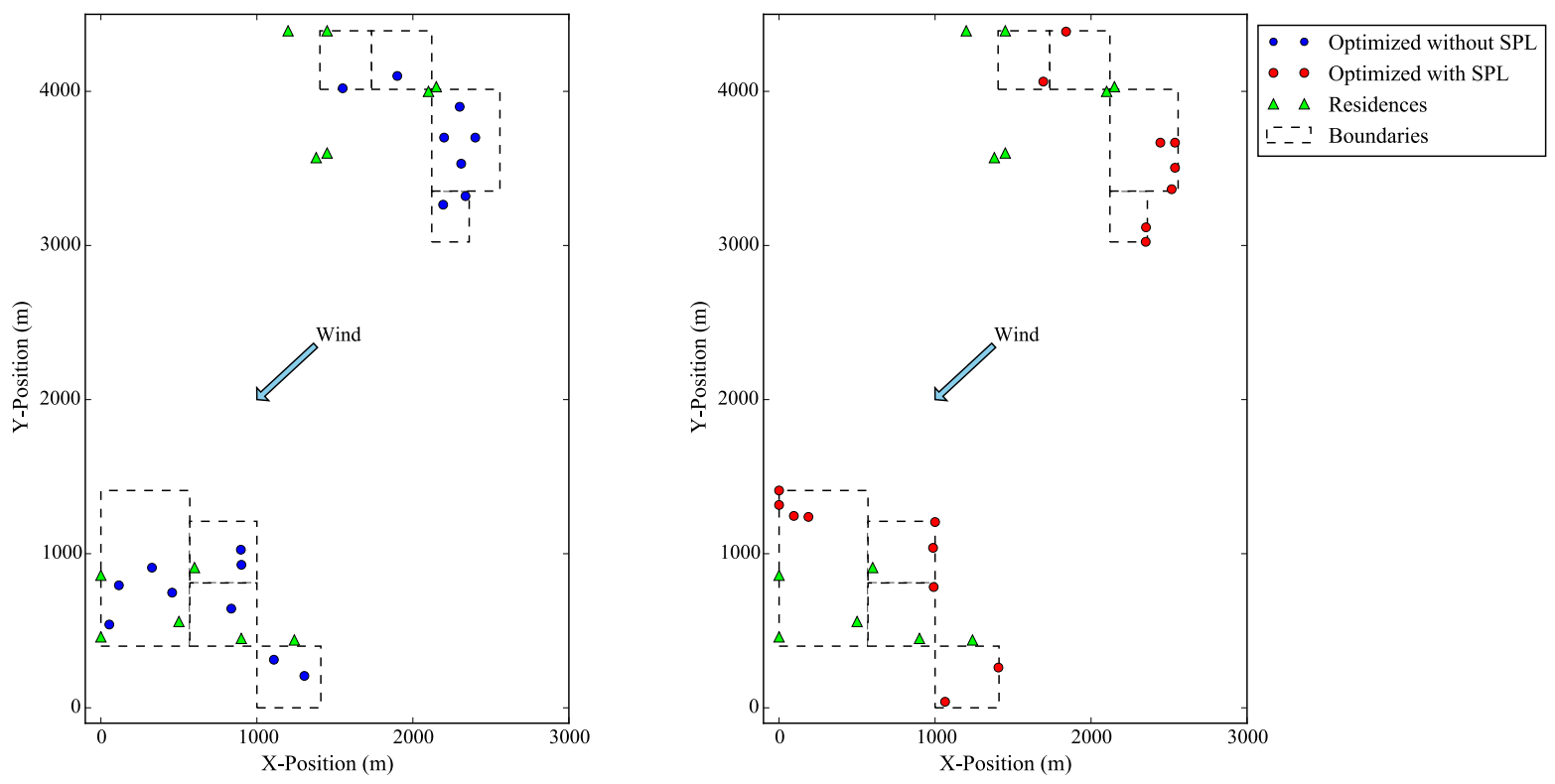

Fig. 7. The optimized layout of the Rosiere Wind Farm showing the optimized locations of the turbines without the SPL constraint in blue and with the SPL constraint in red.
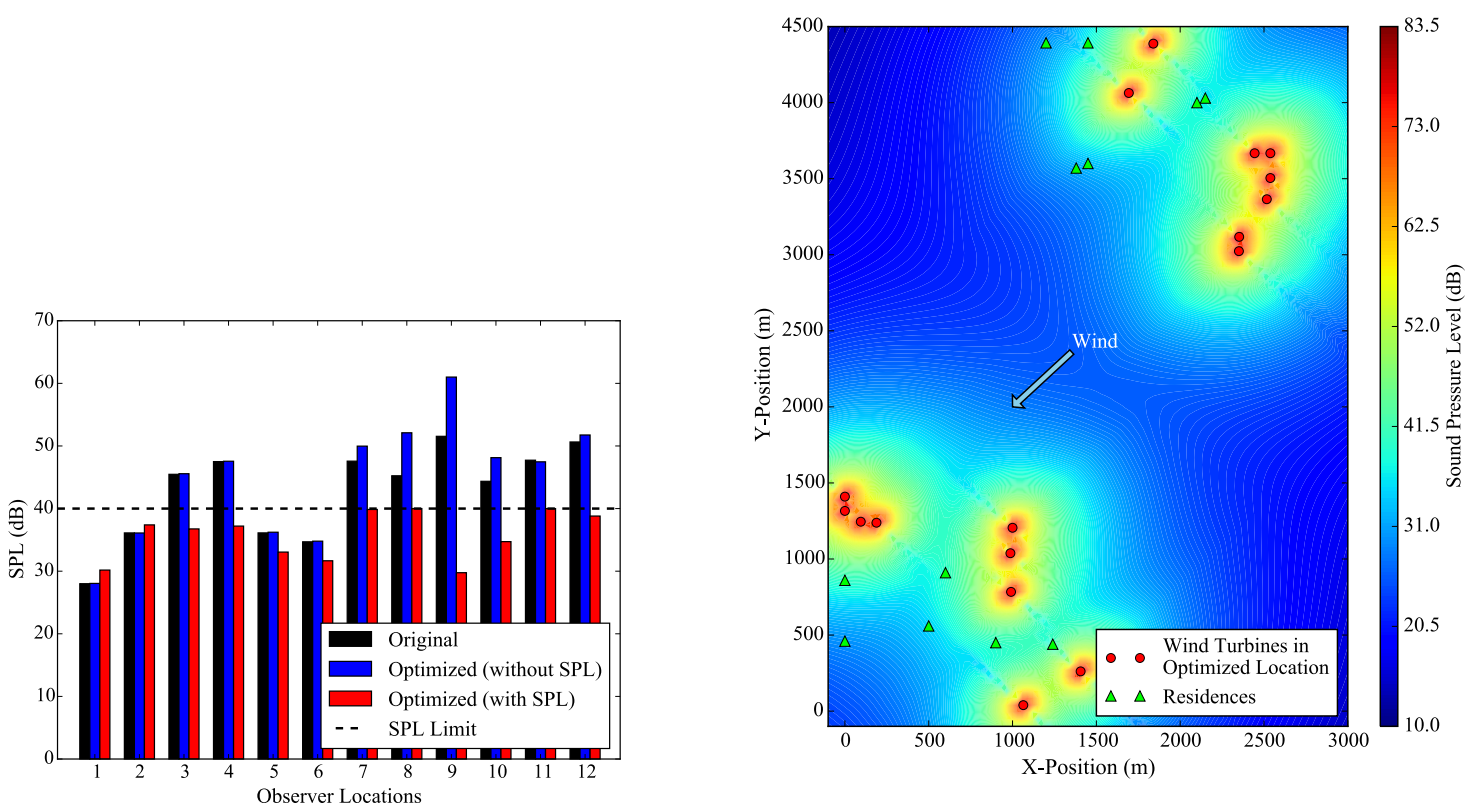

Fig. 8. Results from SPL optimization of the Rosiere Wind Farm. The figure on the left shows a comparison of SPL between the original layout, the optimized layout without SPL constraints, and the optimized layout with SPL constraints. The figure on the right shows the SPL distribution of the Rosiere Wind Farm with the turbines at their optimal locations when the SPL constraint was enforced. 


\section{CONCLUSION}

From this research, we were able to show the impact that optimization had on the power output of a wind farm with wind in a single direction. Overall, we found that enforcing an SPL constraint had a minimal effect in power output and a significant effect in reducing the noise disturbance to residents living near the wind farm. This tradeoff shows potential in that wind farms could sacrifice a small amount of power output for large improvements in eliminating the noise annoyance of the turbines. Although this is a preliminary study, there are positive indications that turbine acoustic problems could be controlled in the initial turbine layout while still producing sufficient power output for the needs of the wind farm.

As described in the methods section, many assumptions and simplifications were made to accommodate the scope of this preliminary research. We plan to make further improvements in future research to include more wind directions in the optimization. In this research, we only looked at the predominant wind as the only wind the wind farm experiences. However, in actuality, wind comes from all different directions and an optimized layout with respect to only one wind direction could be a poor layout when all wind directions are considered. In order to account for different wind directions, future optimization will use annual wind data and place emphasis on wind directions based on how often they occur. This will produce an optimized layout that provides maximum power output over the long-term operation of a wind farm. More observer locations could also be used to ensure that the SPL constraint is enforced for a broader range of residential areas.

Another improvement will be the initial turbine locations used by the optimizer. The solutions presented in this research used only the original wind turbine locations as the starting points of the optimization. Due to this fact, turbines had the potential of being repositioned in locally optimized positions rather than globally optimized positions. Future work will use a multi-start approach where turbine starting locations will be varied to different positions in the wind farm boundaries. This will increase the likelihood of finding a global rather than a local optimum for maximum power output.

\section{REFERENCES}

[1] J. Dabiri, J. Greer, J. Koseff, P. Mois, and J. Peng, "A new approach to wind energy: opportunities and challenges," in AIP Conference Proceedings, 2015.

[2] B. Yang, "Research status on aero-acoustic noise from wind turbine blades," Materials Science and Engineering, vol. 52, 2013.

[3] W. Colby, R. Dobie, G. Leventhall, D. Lipscomb, R. McCunney, M. Seilo, and B. Søndergaard, "Wind turbine sound and health effects: an expert panel review," American Wind Energy Association and Canadian Wind Energy Association, Tech. Rep., December 2009.

[4] (2015) Noise: Data and statistics. World Health Organizaiton. [Online]. Available: http://www.euro.who.int/en/health-topics/environment-andhealth/noise/data-and-statistics

[5] W. Kwong, P. Zhang, D. Romero, J. Moran, M. Morgenroth, and C. Amon, "Wind farm layout optimization considering energy generation and noise propagation," in Proceedings of the ASME 2012 International Design Engineering Technical Conferences \& Computers Information in Engineering Conference, 2012.

[6] T. Brooks, D. Pope, and M. Marcolini, "Aipower self-noise and prediction,” NASA, Tech. Rep., July 1989.

[7] J. Copping and R. Gray. (2011, November) Switch-off for noisy wind farms. The Telegraph. [Online]. Available: http://www.telegraph.co.uk/news/earth/energy/windpower/8901431/ Switch-off-for-noisy-wind-farms.html

[8] E. Rosenbloom, "A problem with wind power," AWEO, Tech. Rep., 2006. [Online]. Available: http://www.aweo.org/problemwithwind.html

[9] (2015) Lissett airfield wind farm. Infinis. [Online]. Available: http://www.infinis.com/our-business/onshore-wind/ouroperations/lissett-airfield/

[10] (2014) Gamma generation: Proven platform-for diverse locations around the world. Nordex. [Online]. Available: http://www.nordexonline.com/en/produkte-service/wind-turbines/n90-25-mw.html

[11] (2015) Rosiere wind farm. Madison Gas and Electric.

[12] (2010) Wind speed distribution for humberside (egnj). RenSMART. [Online]. Available: http://www.rensmart.com/Weather/WindArchive

[13] S. R. Pitts. (2015, April) personal communication. Madison Gas and Electric Company. Post Office Box 1231, Madison, Wisconsin 537011231.

[14] P. M. O. Gebraad, F. W. Teeuwisse, J. W. van Wingerden, P. A. Fleming, S. D. Ruben, J. R. Marden, and L. Y. Pao, "Wind plant power optimization through yaw control using a parametric model for wake effects-a CFD simulation study," Wind Energy, 2014.

[15] P. Moriarty and P. Migliore, "Semi-empirical aeroacoustic noise prediction code for wind turbines," NREL, Tech. Rep., December 2003. 